\title{
ANÁLISIS DE LAS ATRIBUCIONES DE GUARDA Y CUSTODIA DE MENORES EN LAS SENTENCIAS JUDICIALES
}

\author{
ANALYSIS OF THE ATTRIBUTIONS OF \\ GUARDIANSHIP AND CHILD CUSTODY IN \\ JUDICIAL RULINGS
}

\author{
CARLES RODRÍGUEZ-DOMÍNGUEZ ${ }^{1}$, ADOLFO JARNE ${ }^{2}$ Y \\ XAVIER CARBONELL ${ }^{1}$
}

Cómo referenciar este artículo/How to reference this article:

Rodríguez-Domínguez, C., Jarne, A. y Carbonell, X. (2015). Análisis de las atribuciones de guarda y custodia de menores en las sentencias judiciales [Analysis of the attributions of guardianship and child custody in judicial rulings]. Acción Psicológica, 12(1), 1-10. doi: http://dx.doi.org/10.5944/ap.12.1.13383

\begin{abstract}
Resumen
Dada la trascendencia que tienen sobre la vida de los menores involucrados en los procesos de separación o divorcio de sus padres, la atribución de la guarda y custodia de menores está determinada en la jurisprudencia española por la supremacía del Interés Superior del Menor. Aún son escasos en nuestro entorno los estudios de las resoluciones judiciales sobre las atribuciones de la custodia de menores. A fin de analizar las sentencias emitidas en separaciones o divorcios ad litem por los tribunales de familia, se confeccionó un protocolo para dar a conocer en el presente estudio los razonamientos sobre la atribución de la guarda y custodia, y las medidas reguladoras entre las partes emitidas por los tribunales así como para exponer la evolución de la custodia compartida versus exclusiva en el período 2007 a 2013
\end{abstract}

en siete juzgados de familia de la ciudad de Barcelona. Los resultados revelaron evidencias de que todas las sentencias analizadas fueron motivadas, mostraron un incremento a favor de la atribución de la custodia compartida y un decremento de la custodia exclusiva atribuida a favor de la madre en dicho período.

Palabras clave: Guarda y custodia de menores; sentencia judicial; divorcio contencioso.

\begin{abstract}
Given the significance on the lives of children involved in the processes of separation or divorce of their parents, the attribution of custody and child custody is determined in Spanish jurisprudence by the supremacy of the greater interest of the Child. Are
\end{abstract}

Agradecimientos: al Tribunal Superior de Justicia de Cataluña y a los secretarios judiciales responsables de la custodia de los archivos que autorizaron la realización del presente estudio de los expedientes contenciosos en los juzgados de familia, 15, 16, 17, 18, 19, 45 y 51 de la ciudad de Barcelona.

Correspondencia: Carles Rodríguez-Domínguez. Universidad Ramón Llull. Email: carlesrd@blanquerna.url.edu

${ }^{1}$ Universidad Ramón Llull

${ }^{2}$ Universidad de Barcelona

Recibido: 24 de octubre de 2014

Aceptado: 05 de marzo de 2015 
still rare in our environment studies of judicial decisions on the powers of the custody of children. In order to analyze the judgments in separation or divorce ad litem by the family courts, a protocol was drawn to publicize in this study reasoning about the attribution of the custody, and regulatory measures among parts issued by the courts and for explaining the evolution of shared versus sole custody in the period 2007-2013 in seven courts in Barcelona city. The results revealed evidence that all the sentences analyzed were motivated, showed an increase in favor of the attribution of joint custody and a decrease in sole custody attributed in favor of the mother in that period.

Keywords: Care and custody of minors; judicial judgment; divorce litigation.

\section{Introducción}

La atribución de la guarda y custodia de menores está determinada en la jurisprudencia española por la supremacía del Interés Superior del Menor (en adelante ISM), objetivo fundamental del Derecho de Familia, en correspondencia con el conjunto de instituciones y ámbitos en que su persona o patrimonio pueden ser afectados por medidas que otros tomen en su nombre (de Torres, 2011).

No obstante ello, al estudiar los razonamientos judiciales en procesos de separación de 782 sentencias judiciales correspondientes al período 1993-1999 se observó que el $91.6 \%$ de las atribuciones de la guarda y custodia fueron asignadas a las madres y el $8.4 \%$ a los padres (Arce, Fariña y Seijo, 2005). Según sus autores, el $57.3 \%$ de las sentencias no se regían por criterio alguno. Como conclusión, señalaron que las decisiones sobre la guarda y custodia de los menores podrían no defender el ISM.

Otro estudio, posterior a la entrada en vigor de la Ley 15/2005 de 8 de julio por la que se modifican el Código Civil y la Ley de Enjuiciamiento Civil en materia de separación y divorcio, puso de manifiesto un cambio de tendencia en lo que se refiere a la asignación de la guarda y custodia: el $71.5 \%$ de las sentencias fueron favorables a la madre, frente al $22.5 \%$ que fueron atribuidas al padre (Novo, Quinteiro y Vázquez, 2013). Según estos autores todas las sentencias analizadas contenían algún criterio y se apreció un progreso en la argumentación con referencia al estudio anterior en el cual se manifestaba una carencia de motivación. También se apreció un cambio progresivo de tendencia en relación a la regulación anterior, frente a otros estudios que seguían manifestando el predominio del modelo de atribución de la custodia a la madre (Catalán et al., 2008).

Una encuesta a psicólogos forenses y juristas reveló su predilección por la custodia exclusiva, con un amplio régimen de visitas a favor del progenitor no custodio. La mayoría de magistrados escogieron incluir pernoctas inter semanales que, en la práctica, podía reflejar un reparto próximo al $50 \%$ del tiempo de permanencia del menor con ambos progenitores. Más allá del recelo que parecía generar la custodia compartida, psicólogos y magistrados opinaron que el resultado de este régimen es positivo y que la discrepancia entre la preferencia enunciada y la información lograda, podría relacionarse con la novedad de su regulación jurídica (Arch y Jarne, 2008).

El Instituto Nacional de Estadística (2013) estimó que en 2012 se produjeron 110.764 disoluciones, de las que 104.262 fueron divorcios, 6.369 separaciones y 133 nulidades. Conviene resaltar que el $34.1 \%$ de los divorcios fueron no consensuados, y un $27.9 \%$ de las separaciones fueron contenciosas. La atribución de la custodia de los hijos menores a la madre $(75.1 \%)$ en las rupturas matrimoniales disminuyó respecto al año anterior $(81.7 \%)$ y aumentó la atribución de la custodia al padre en un 9.7\% de las disoluciones frente al 5.3\% de 2011 .

De Torres (2011) analiza varias sentencias del Tribunal Superior de Justicia de las que ha sido ponente Encarnación Roca i Trías (STS, 1ª R J 2009/4581; STS, $1^{a}$, R J 2009/7257). Se aprecia una especial afinidad por la custodia compartida, pues siempre que se den las circunstancias objetivas necesarias ha de ser adoptada por así exigirlo el ISM, transformando el modelo tradicional que concebía como regla general la custodia a favor de uno de los progenitores (habitualmente la madre) y esporádicamente la custodia compartida. Este esquema parece superado en favor de concebir que la norma general sea la custodia compartida, y sólo cuando ésta fuese inviable, atribuir la custodia exclusiva (de Torres, 2011).

Por otra parte, la Ley 11/1981 de 13 de mayo, de modificación del Código Civil en materia de filiación, patria potestad y régimen económico del matrimonio, la Ley 11/90 de 15 de octubre de 1990 sobre reforma del Código Civil, en aplicación del principio de no discriminación por razón de sexo, y posteriormente, la Ley 25/2010 de 29 de Julio, del Libro Segundo del Código Civil de Cataluña relativo a la persona y la familia proporcionan los criterios para perfilar el ISM en relación a las condiciones del caso particular cuando se hayan de implantar las responsabilidades parentales sobre los hijos menores tras la ruptura matrimonial o de la convivencia en pareja, y en el desarrollo de la potestad parental o de la tutela (Institut de Dret Privat Europeu i Comparat, 2010). 
Dado los escasos estudios de las resoluciones judiciales atendiendo al análisis de la motivación o de los razonamientos formales e informales contenidos en las sentencias (Muñoz, 2011) se justifica la necesidad de investigar cómo se estructuran los razonamientos y las atribuciones de las sentencias judiciales en los juzgados de familia tras la publicación de la Ley 25/2010. Por ello, el objetivo general de la presente investigación fue analizar las sentencias relativas a las separaciones o divorcios ad litem de familias con hijos menores, emitidas por los magistrados de siete juzgados de familia de la ciudad de Barcelona.

Los objetivos específicos fueron:

1) Conocer respecto de las responsabilidades derivadas de la potestad sobre los hijos, los razonamientos sobre: (a) la atribución de la guarda y custodia a la madre, al padre; (b) la existencia o no de acuerdo entre las partes; (c) si se solicitó la guarda compartida, exclusiva, repartida y qué tipo de régimen de visitas; (d) si se solicitó el aumento de la pensión de alimentos; (e) los acuerdos sobre gastos extras; (f) los cambios de residencia; (g) la división de la cosa en común (padre o madre); $\mathrm{y}$, por último, (h) el mantenimiento de la atribución del uso de la vivienda a uno $\mathrm{u}$ otro progenitor.

2) Conocer las medidas reguladoras entre las partes sobre: (a) la atribución de la guarda y custodia a la madre, al padre, atribución compartida o repartida, si fue el caso; (b) la atribución del régimen de visitas amplio, restringido, o en el punto de encuentro; (c) el tipo de entendimiento entre los padres respecto de la parentalidad y de los progenitores con los menores.

Las hipótesis de la presente investigación fueron:

Primera hipótesis. Se observará un decremento de las atribuciones de la guarda y custodia a la madre, a partir de la implantación de la Ley 25/2010, y un incremento de la custodia compartida. Aunque se intenta contrastar estos resultados con los estudios anteriores (Arce et al., 2005; INE, 2013; Novo et al., 2013), se advierte al lector que la comparación exacta no es posible porque las muestras tienen procedencias diferentes.

Segunda hipótesis. La atribución de la custodia compartida será más frecuente en Cataluña que el resto de Comunidades Autónomas y en las ciudades autónomas Ceuta y Melilla.

Tercera hipótesis. Se advertirán cambios en los razonamientos judiciales, con motivo de la implantación de la Ley 25/2010, entre el período 2007-2010 y el período 2010-2013.
Cuarta hipótesis. Se hallarán diferencias significativas en las atribuciones de la guarda y custodia de menores y del régimen de visitas paterno-filiales con motivo de la implantación de la Ley 25/2010, entre el período 20072010 y el período $2010-2013$.

Quinta hipótesis. Se encontrarán diferencias en las propuestas de la custodia exclusiva/ compartida de los informes psicológicos periciales de los equipos psicosociales (EPS) respecto de los privados con formación específica forense (PPCF) y de los informes privados sin formación específica forense (PPSF).

Sexta hipótesis. Se observarán diferencias en la valoración positiva expresada en las sentencias por los tribunales entre los EPS y los informes privados (PP).

\section{Método}

\section{Muestra}

Se analizaron 111 expedientes judiciales contenciosos que contenían informe pericial psicológico y la sentencia emitida en primera instancia por los Juzgados de Familia, $15,16,17,18,19,45$ y 51 , de la ciudad de Barcelona entre enero de 2007 y diciembre de 2013. De estos, 45 informes periciales los firmaron psicólogos en ejercicio privado (PP) y 66 profesionales de los equipos psicosociales adscritos a los juzgados de familia (EPS). Treinta y seis sentencias fueron emitidas en el período 2007-2010 y 75 sentencias en el período 2010-2013.

\section{Materiales}

Para la recogida de datos se confeccionó un protocolo elaborado por los autores que recogía información sobre los razonamientos acerca de las responsabilidades derivadas de la patria potestad de los hijos y sobre las atribuciones judiciales acerca de las medidas reguladoras entre las partes de la custodia y del régimen de visitas del progenitor no custodio.

\section{Procedimiento}

El estudio obtuvo resolución favorable del Comité de Ética de Investigación de la Universidad Ramon Llull. Se solicitó autorización al Tribunal Superior de Justicia de Cataluña que trasladó la solicitud a los secretarios judiciales de los juzgados de familia. 
Tabla 1

Datos globales de la muestra de 111 casos contenciosos del período 2007-2013 de los Juzgados de Familia, 15, 16, 17, 18,19, 45 y 51 de la ciudad de Barcelona

\begin{tabular}{|c|c|c|}
\hline \multirow{2}{*}{ El Tribunal razona la existencia de acuerdo entre las partes } & Con acuerdo & $12,76 \%$ \\
\hline & Sin acuerdo & $82,40 \%$ \\
\hline \multirow{3}{*}{ El tribunal razona visitas intersemanales con el progenitor no custodio } & $\mathrm{Si}$ & $89.40 \%$ \\
\hline & No & $05.8 \%$ \\
\hline & Acuerda suspensión & $04.80 \%$ \\
\hline \multirow{3}{*}{ El Tribunal razón la pensión de alimentos } & Sí & $81.60 \%$ \\
\hline & No procede & $04.60 \%$ \\
\hline & Acuerda la disminución & $03.90 \%$ \\
\hline \multirow{2}{*}{ El Tribunal razón el acuerdo entre las partes sobre los gastos extraordinarios } & Sí & $58.60 \%$ \\
\hline & No procede & $41.40 \%$ \\
\hline \multirow{2}{*}{ El Tribunal razona el cambio de residencia de una de las partes } & Sí & $16.70 \%$ \\
\hline & No procede & $83.30 \%$ \\
\hline \multirow{2}{*}{ El Tribunal razona la división de la cosa en común (vivienda) } & Sí & $13.30 \%$ \\
\hline & No procede & $86.70 \%$ \\
\hline \multirow{4}{*}{$\begin{array}{l}\text { El Tribunal razona el mantenimiento de la atribución del uso de la vivienda a la } \\
\text { madre }\end{array}$} & A la madre & $74.50 \%$ \\
\hline & Al padre & $16.30 \%$ \\
\hline & Compartida & $05.10 \%$ \\
\hline & Venta del bien & $02.00 \%$ \\
\hline \multirow{2}{*}{ El Tribunal valora el entendimiento entre las partes } & Bueno & $21.10 \%$ \\
\hline & Malo & $78.90 \%$ \\
\hline \multirow{2}{*}{ El Tribunal valora el entendimiento entre padre e hijos } & Bueno si & $76.90 \%$ \\
\hline & Malo & $23.10 \%$ \\
\hline \multirow{2}{*}{ El Tribunal valora el entendimiento entre madre e hijos } & Bueno & $83.60 \%$ \\
\hline & Malo & $16.40 \%$ \\
\hline \multirow{4}{*}{ El Tribunal atribuye la Guarda y Custodia } & A la madre & $69.10 \%$ \\
\hline & Al padre & $12.70 \%$ \\
\hline & Compartida & $14.50 \%$ \\
\hline & Retirada & $03.65 \%$ \\
\hline \multirow{3}{*}{ El Tribunal atribuye el régimen de contactos con el progenitor no custodio } & Amplio & $51.60 \%$ \\
\hline & Estándar & $24.20 \%$ \\
\hline & Con restricciones & $24.20 \%$ \\
\hline
\end{tabular}

\section{Diseñoyvariables}

Se trata de un estudio ex post facto retrospectivo comparativo de grupos de tipo transversal preseleccionados de archivo con sentencia e informe pericial psicológico. Al tratarse de un estudio exploratorio no es posible asegurar el control de variables extrañas. No obstante, se excluyeron los expedientes con otro tipo de informes que no fueran exclusivamente firmados por psicólogos privados o equipos psicosociales adscritos a los juzgados. Se utilizó la técnica de mantenimiento de constancia de las condiciones: (a) Informe pericial firmado por psicólogo privado y por profesional del equipo psicosocial adscrito al juzgado, (b) mediante sentencia judicial emitida en Primera Instancia en Juzgado especializado en Familia.

Para el estudio se realizó un análisis previo de sentencias para identificar los criterios de asignación de guarda y custodia que utilizaban los jueces en base a la estructura legal. A partir de ello, se utilizó un protocolo confeccionado por los autores, orientado a la exploración de los criterios de asignación de guarda y custodia. La variable independiente fue la introducción de la Ley 25/2010, de 29 de Julio, del libro $2^{\circ}$ del Código Civil de Cataluña. Las variables dependientes fueron las sentencias judiciales emitidas entre enero de 2007 y junio de 2010 y entre julio de 2010 y diciembre de 2013.

El tratamiento estadístico tuvo finalidad descriptiva para lo cual se calcularon descriptores, frecuencias y análisis $\chi^{2}$ de las variables para averiguar si habían o no diferencias significativas $(p<.05, p<.01, p<.001)$ 
Tabla 2

Evolución de la atribución de la guarda y custodia en sentencias judiciales

\begin{tabular}{|c|c|c|c|c|c|}
\hline Fuente & Período & Al padre \% & A la madre $\%$ & Compartida \% & Retirada \% \\
\hline Arce et al., $(2005)^{1}$ & 1993-1999 & 8.44 & 91.56 & - & - \\
\hline Novo et al., (2005) ${ }^{1}$ & 2005 & 22.05 & 71.05 & - & - \\
\hline $\operatorname{INE}(2013)^{1}$ & 2012 & 9.07 & 75.01 & 14.6 & 0.06 \\
\hline Estudio actual $^{2}$ & 2007-2013 & 12.70 & 69.10 & 14.50 & 3.60 \\
\hline
\end{tabular}

\section{Resultados}

Los datos referidos a los razonamientos judiciales emitidos en el período 2007-2013 se muestran en la Tabla 1. En ella se observa que el magistrado razonó, entre otros argumentos legales los siguientes aspectos: (a) sostuvo criterios relativos a la existencia o no de acuerdo entre las partes; (b) las visitas inter semanales del progenitor no custodio; (c) la pensión de alimentos; (d) los gastos extraordinarios; en su caso, los cambios de residencia de los progenitores; (e) razonamientos sobre la división de la cosa en común (vivienda); (f) sobre el mantenimiento de la atribución del uso de la vivienda; (g) sobre el entendimiento entre las partes; 8) sobre entendimiento entre progenitores e hijos; (h) sobre la atribución de la guarda y custodia, y el régimen de contactos con el progenitor no custodio; i) razonó otorgar la guarda y custodia a la madre $(68.8 \%)$; (j) al padre $(12.8 \%)$; (k) compartida $(11.9 \%)$, (1) repartida $(2.8 \%)$, (m) retirada $(2.8 \%)$, y (n) no procedió $(0.9 \%)$.
Tomando como referencia diferentes hitos jurídicos, la Tabla 2 muestra un estudio comparativo sobre el período 1993-1999, el período posterior a la ley del divorcio (Ley 15/2005), y el período marcado por el nuevo Código Civil de Cataluña (Ley 25/2010) del presente estudio, se observaron los resultados para comprobar los cambios que se han producido respecto a la atribución de la guarda y custodia de menores. Considere el lector que el presente estudio sólo hace referencia a expedientes judiciales contenciosos con informe pericial psicológico incluido, sin incluir divorcios de mutuo acuerdo.

En la Tabla 3 se presentan los datos de la atribución de la guarda y custodia referidos al año 2012, ordenados por Comunidades Autónomas (INE, 2013) de mayor a menor en función de la atribución de la custodia compartida. Como se puede observar la evolución hacía la custodia compartida muestra variaciones que oscilan desde un $46.76 \%$ hasta un $3.55 \%(\mu=9.11, \mathrm{Md}=6.29$, $\sigma$ $=9.58)$.

\section{Tabla 3}

Guarda y Custodia año 2012 por Comunidades Autónomas. Fuente INE 2013, adaptado por Rodríguez-Domínguez, et al.

\begin{tabular}{lrrrr}
\hline $\begin{array}{l}\text { Comunidad } \\
\text { autónoma }\end{array}$ & $\begin{array}{r}\text { Separaciones, } \\
\text { divorcios y } \\
\text { nulidades }\end{array}$ & $\begin{array}{r}\text { Exclusiva al padre \% } \\
\text { Melilla }\end{array} \quad \begin{array}{r}\text { Custodia } \\
\text { Cataluña (a) }\end{array} \quad \begin{array}{r}\text { Custodia Exclusiva } \\
\text { a la madre \% }\end{array}$ & $\begin{array}{r}\text { Custodia } \\
\text { Compartida \% }\end{array}$ \\
Aragón (a) & 19801 & 4.97 & 21.39 & $46.76(\mathrm{~b})$ \\
Illes Balears & 2483 & 5.81 & 33.07 & 14.11 \\
C. Valenciana (a) & 2838 & 4.79 & 34.55 & 13.25 \\
País Vasco & 12785 & 7.08 & 30.83 & 10.53 \\
La Rioja & 4100 & 5.09 & 38.46 & 10.13 \\
Ceuta & 641 & 5.09 & 38.00 & 7.34 \\
C. de Madrid & 217 & 4.21 & 42.12 & 7.02 \\
Foral Navarra (a) & 15317 & 1.38 & 30.87 & 6.91 \\
Canarias & 1254 & 4.62 & 40.00 & 6.43 \\
Asturias & 5974 & 6.87 & 37.00 & 6.29 \\
Castilla La Mancha & 2641 & 5.07 & 38.34 & 6.14 \\
Castilla y León & 4242 & 4.12 & 36.34 & 5.67 \\
Cantabria & 4400 & 6.01 & 46.88 & 5.28 \\
Galicia & 1470 & 4.56 & 42.75 & 5.20 \\
Extremadura & 6196 & 4.96 & 41.02 & 3.10 \\
Andalucía & 2009 & 5.36 & 37.68 & 4.96 \\
Región de Murcia & 20393 & 5.17 & 46.04 & 4.67 \\
\hline Nota (a) & 3375 & 4.73 & 52.11 & 3.89 \\
\hline
\end{tabular}

Nota. (a) Comunidades autónomas con legislación propia de custodia compartida. (b) Ordenado de mayor a menor 
Tabla 4

Razonamientos judiciales sobre la guarda y custodia en asuntos contenciosos

\begin{tabular}{|c|c|c|c|c|c|}
\hline & & \multicolumn{2}{|c|}{ Período } & \multicolumn{2}{|c|}{ Estadístico } \\
\hline & & $\begin{array}{l}2007- \\
2010\end{array}$ & $\begin{aligned} 2011- \\
2013\end{aligned}$ & $x^{2}$ & $P$ valor \\
\hline $\begin{array}{l}\text { El Tribunal razona la Guarda y Custodia } \\
\text { Compartida }\end{array}$ & $\begin{array}{l}\text { Sí } \\
\text { No }\end{array}$ & $\begin{array}{r}8.6 \\
91.4 \\
\end{array}$ & $\begin{array}{l}25.4 \\
74.6 \\
\end{array}$ & 4.030 & $.037^{\star}$ \\
\hline $\begin{array}{l}\text { El Tribunal razona la Guarda y Custodia } \\
\text { Repartida }\end{array}$ & $\begin{array}{l}\text { Sí } \\
\text { No }\end{array}$ & $10 \overline{-}$ & $\begin{array}{r}7.5 \\
92.5\end{array}$ & 2.734 & .146 \\
\hline $\begin{array}{l}\text { El Tribunal reconoce que se da acuerdo entre } \\
\text { las partes }\end{array}$ & $\begin{array}{l}\text { Acuerdo } \\
\text { Desacuerdo }\end{array}$ & $\begin{array}{r}2.8 \\
97.2 \\
\end{array}$ & $\begin{array}{l}25.0 \\
75.0\end{array}$ & 8.175 & $.002^{* *}$ \\
\hline $\begin{array}{l}\text { El Tribunal razona visitas intersemanales al } \\
\text { progenitor no custodio }\end{array}$ & $\begin{array}{l}\text { Sí } \\
\text { No } \\
\text { Suspende visitas }\end{array}$ & $\begin{array}{r}77.8 \\
13.9 \\
8.3 \\
\end{array}$ & $\begin{array}{r}95.6 \\
1.5 \\
2.9 \\
\end{array}$ & 8.550 & $.014^{*}$ \\
\hline $\begin{array}{l}\text { El Tribunal razona la Pensión de Alimentos } \\
\text { de los hijos }\end{array}$ & $\begin{array}{l}\text { Sí } \\
\text { No } \\
\text { Disminuir la aportación }\end{array}$ & $\begin{array}{r}94.4 \\
5.6 \\
-\end{array}$ & $\begin{array}{r}74.6 \\
19.4 \\
6.0 \\
\end{array}$ & 6.360 & $.042^{*}$ \\
\hline $\begin{array}{l}\text { El Tribunal razona la Pensión de Alimentos } \\
\text { de los hijos }\end{array}$ & $\begin{array}{l}\text { Sí } \\
\text { No } \\
\text { Disminuir la aportación }\end{array}$ & $\begin{array}{r}94.4 \\
5.6 \\
-\end{array}$ & $\begin{array}{r}74.6 \\
19.4 \\
6.0 \\
\end{array}$ & 6.360 & $.042^{*}$ \\
\hline $\begin{array}{l}\text { El Tribunal razona sobre el acuerdo entre las } \\
\text { partes sobre gastos extras }\end{array}$ & $\begin{array}{l}\text { Acuerdo } \\
\text { Desacuerdo }\end{array}$ & $\begin{array}{l}66.7 \\
33.3\end{array}$ & $\begin{array}{l}53.8 \\
46.2\end{array}$ & 1.568 & .149 \\
\hline $\begin{array}{l}\text { El Tribunal razona sobre cambios de residen- } \\
\text { cia del progenitor }\end{array}$ & $\begin{array}{l}\text { Sí } \\
\text { No procede }\end{array}$ & $\begin{array}{l}13.9 \\
86.1\end{array}$ & $\begin{array}{l}18.5 \\
81.5\end{array}$ & .333 & .392 \\
\hline $\begin{array}{l}\text { El Tribunal razona sobre la solicitud de divi- } \\
\text { sión de la cosa común (vivienda) }\end{array}$ & $\begin{array}{l}\text { Sí } \\
\text { No procede }\end{array}$ & $\begin{array}{l}13.9 \\
86.1\end{array}$ & $\begin{array}{l}13.0 \\
87.0\end{array}$ & .016 & .569 \\
\hline $\begin{array}{l}\text { El Tribunal razona mantenimiento de la atri- } \\
\text { bución del uso de la vivienda al progenitor } \\
\text { custodio }\end{array}$ & $\begin{array}{l}\text { A la madre } \\
\text { Al padre } \\
\text { Compartida } \\
\text { Venta del bien } \\
\text { No tienen vivienda }\end{array}$ & $\begin{array}{r}75.0 \\
19.4 \\
2.8 \\
2.8 \\
-\end{array}$ & $\begin{array}{r}74.2 \\
14.5 \\
6.4 \\
1.6 \\
3.2 \\
\end{array}$ & 2.830 & .726 \\
\hline $\begin{array}{l}\text { El Tribunal razona sobre el entendimiento } \\
\text { entre las partes }\end{array}$ & $\begin{array}{l}\text { Buen entendimiento } \\
\text { Mal entendimiento }\end{array}$ & $\begin{array}{l}11.1 \\
88.9\end{array}$ & $\begin{array}{l}26.0 \\
74.0\end{array}$ & 3.222 & .057 \\
\hline $\begin{array}{l}\text { El Tribunal razona sobre el entendimiento } \\
\text { entre el padre e hijo/s }\end{array}$ & $\begin{array}{l}\text { Buen entendimiento } \\
\text { Mal entendimiento }\end{array}$ & $\begin{array}{l}74.3 \\
25.7\end{array}$ & $\begin{array}{l}78.1 \\
21.9\end{array}$ & .192 & .417 \\
\hline $\begin{array}{l}\text { El Tribunal razona sobre el entendimiento } \\
\text { entre madre e hijo/s }\end{array}$ & $\begin{array}{l}\text { Buen entendimiento } \\
\text { Mal entendimiento }\end{array}$ & $\begin{array}{l}86.1 \\
13.9 \\
\end{array}$ & $\begin{array}{l}82.4 \\
17.6 \\
\end{array}$ & .239 & .424 \\
\hline
\end{tabular}

Nota. Sentencias anteriores y posteriores a la Ley 25/2010, de 29 de Julio, del libro $2^{\circ}$ del Código Civil de Cataluña (en $\%) .{ }^{*} p<.05 ;{ }^{* *} p<.001$

La Tabla 4 recoge los considerandos o razonamientos judiciales sobre la guarda y custodia de menores, analizando las sentencias de divorcios contenciosos relativas a los períodos 2007-2010 y 2011-2013. Se observan diferencias estadísticamente significativas entre ambos períodos, al razonar la guarda y custodia compartida $\left(\chi^{2}=4.030, p<.05\right)$, al acuerdo entre las partes $\left(\chi_{2}=8.175, p<.001\right)$, respecto a los razonamientos de las visitas inter semanales con el progenitor no custodio $\left(\chi^{2}=8.550, p<.05\right)$ y en los razonamientos sobre la pensión de alimentos $(\chi 2=6.360, p<.05)$. Por otra parte, los razonamientos sobre la guarda y custodia repartida, los acuerdos sobre gastos extraordinarios, cambios de residencia de uno de los progenitores, división de la cosa en común, razonamientos sobre el entendimiento entre las partes, entendimiento entre padre e hijos, y madre e hijos, no hallaron diferencias significativas $(p>.05)$.
La Tabla 5 muestra las disposiciones o atribuciones judiciales de las sentencias respecto a la guarda y custodia de menores y tipo de régimen de visitas establecido con el progenitor no custodio, tomando en consideración los períodos 2007-2010 y 2011-2013 en función del cambio legislativo (Ley 25/2010). En ella no se observan diferencias significativas en la guarda y custodia de menores, ni en la aplicación del régimen de visitas del menor con el progenitor no custodio $(p>.05)$.

La Tabla 6 muestra las propuestas de los informes periciales en relación a la custodia exclusiva o compartida en la que se observan diferencias significativas $\left(\chi^{2}=\right.$ $15.679, p<.05)$ a favor de los equipos psicosociales, respecto de los profesionales privados con y sin formación específica forense. Por su parte, los tribunales apreciaron los informes emitidos por los equipos psicosociales frente a los informes periciales privados, con una diferencia significativa $(\chi 2=7.527, p<.05)$. 
Tabla 5

Atribuciones Judiciales en las Sentencias de la Guarda y Custodia y régimen de visitas

\begin{tabular}{|c|c|c|c|c|c|c|}
\hline \multirow{2}{*}{ Período } & \multicolumn{6}{|c|}{ Atribución de la Guarda y Custodia } \\
\hline & Al padre & A la madre & Compartida & Retirada & $x^{2}$ & $P$ valor \\
\hline $2007-2010$ & 16.7 & 75.0 & 8.3 & 0.0 & & \\
\hline $2011-2013$ & 10.8 & 66.2 & 17.6 & 5.4 & 4.289 & .232 \\
\hline \multirow{2}{*}{ Período } & \multicolumn{6}{|c|}{$\begin{array}{l}\text { Régimen de Visitas } \\
\end{array}$} \\
\hline & Amplio & Estándar & & Restringido & $X^{2}$ & $P$ valor \\
\hline $2007-2010$ & 58.6 & 20.7 & & 20.7 & 820 & 661 \\
\hline 2011-2013 & 48.4 & 25.8 & & 25.8 & .829 & .661 \\
\hline
\end{tabular}

Nota. Sentencias anteriores y posteriores a la Ley 25/2010, de 29 de Julio, del libro $2^{\circ}$ del Código Civil de Cataluña (\%). Amplio: incluye fines de semana de viernes a lunes y pernoctas intersemanales alternas con el progenitor no custodio. Estándar: incluye el fin de semana. Restringido: se incluye unas horas un día (sábado o domingo) o cuando se limita al punto de encuentro supervisado institucionalmente.

\section{Discusión}

La introducción de la Ley 25/2010 representa un importante cambio en dirección a la atribución de la custodia compartida y al principio de no discriminación por razón de sexo conforme a la Ley 11/1990. Una primera respuesta a la pregunta sobre qué es lo que toma en cuenta el Tribunal en sus motivaciones al dictar sentencia, se encontró en sus manifestaciones referidas al texto legal: estatal, autonómico y/o en las sentencias que han sentado jurisprudencia. En referencia a Cataluña, se observa "cómo" los criterios quedan especialmente determinados, entre otros, por el Artículo 233-8. Responsabilidad parental, al artículo 236-17.1.2 y el artículo 233-9 (Ley 25/2010).

"1. La nulidad del matrimonio, el divorcio o la separación judicial no alteran las responsabilidades que los progenitores tienen respecto de los hijos de acuerdo con el artículo 236-17.1. En consecuencia, estas responsabilidades mantienen el carácter compartido, $y$ en la medida que sea posible, se han de ejercer conjuntamente."

"2. Los cónyuges, para determinar cómo se han de ejercer las responsabilidades parentales, han de presentar sus propuestas del plan de parentalidad, con el contenido que establece el artículo 233-9.

Tabla 6
La autoridad judicial, en el momento de decidir sobre las responsabilidades parentales de los progenitores, ha de atender de forma prioritaria el interés superior del menor."

Tomando en cuenta este aspecto y entendiendo que el estudio se refiere a asuntos contenciosos se destaca una serie de matices sobre las sentencias judiciales en la guarda y custodia de menores. Los magistrados razonaron todas sus sentencias conforme a los principios legales antedichos: en relación a los estudios anteriores (Arce et al., 2005; Catalán et al., 2008; Novo et al., 2013) conviene matizar que las conclusiones emitidas por los magistrados están basadas en la Ley y que los aspectos psicológicos los aportan los informes periciales psicológicos por profesionales acreditados en su función auxiliar de asesoramiento de la Justicia. Las atribuciones sobre la custodia de menores y los regímenes de visita con el progenitor no custodio se basaron en los razonamientos expresados en las sentencias y referidas a los informes psicológicos de los equipos psicosociales adscritos a los juzgados y en su caso a los informes psicológicos privados (a veces denominados de parte).

En relación a la primera hipótesis, cabe señalar que durante el período 2007-2013 se atribuyó la guarda y custodia a la madre en un $69.1 \%$ de las sentencias procedentes de expedientes contenciosos, dato que sobresale de forma relativa, sí se confronta con las debidas reser-

Propuestas del tipo de custodia en los informes periciales y apreciación del tribunal de los informes periciales

\begin{tabular}{llll}
\hline & \multicolumn{2}{l}{ Propuestas de la Guarda y Custodia } & EPS \\
\hline Informes periciales & $\boldsymbol{P P S F}$ & $\boldsymbol{P P C F}$ & 76.6 \\
\hline Custodia exclusiva & 56.2 & 53.3 & 14.1 \\
Custodia compartida & 31.3 & 23.3 & \\
& & & \\
\hline Valoración del Tribunal & $\boldsymbol{P P}$ & $\boldsymbol{E P S}$ & \\
\hline Positiva & 42.2 & 66.7 & \\
\hline
\end{tabular}

Nota. PPSF: Psicólogo privado sin formación forense, PPCF: Psicólogo Privado Con Formación Forense, EPS: Equipo

Psicosocial del Juzgado, PP: Psicólogo Privado. ${ }^{*} p<.05$. 
vas, con el $75.0 \%$ del estado español (INE, 2013) o del $71.0 \%$ en el 2005, (Novo et al., 2013) o el $91.6 \%$ del período 1993-1999 (Arce et al., 2005). Por tanto, se ha producido un decremento en la atribución de la guarda y custodia a la madre en beneficio de un incremento de la custodia compartida.

De acuerdo con Arch y Jarne (2008) las manifestaciones sobre la novedad jurídica, en este estudio sugieren confirmar la tendencia al cambio en los juzgados de Barcelona hacía la custodia compartida. Se abren aquí diversas cuestiones para futuros estudios: ¿Qué diferencias hay, respecto al tipo de custodia, en las sentencias emitidas por tribunales especializados en Derecho de familia y emitidas por tribunales de primera instancia e instrucción que han de entender en materias tanto civiles como penales? ¿Qué diferencias se plantean, respecto a la custodia compartida, en las sentencias de divorcios contenciosos respecto de los divorcios por mutuo acuerdo a nivel nacional?

Respecto a la segunda hipótesis, Cataluña ocupa el segundo lugar de España con el $14.1 \%$ de custodias compartidas de un total de 19.801 rupturas de la relación conyugal, justo después de Melilla que alcanza el $46.8 \%$ de un total de 201 rupturas de la relación conyugal. A pesar de tener legislaciones propias sobre la custodia compartida, Aragón ocupa el tercer lugar (Ley 2/2010), la Comunidad Valenciana el quinto lugar (Ley 5/2011), y la Comunidad Foral de Navarra el décimo lugar (Ley Foral 3/2011). Como se puede observar, la evolución hacía la custodia compartida muestra variaciones que oscilan desde un $46.76 \%$ hasta un $3.55 \%$. ¿Qué variables pueden explicar estas variaciones cuándo la Ley es igual para todos? Estas diferencias entre las distintas Autonomías del territorio español requieren nuevos estudios que analicen las razones de tales diferencias, que quizás, se podría deber a que la penetración progresiva de la custodia compartida aumenta cuando existe una legislación específica. En este sentido, en materia tan sensible como es el ISM, no podemos dejar de preguntarnos si el legislador debería estudiar la posibilidad de realizar cambios normativos respecto a la conveniencia de que fueran exclusivamente los tribunales especializados en Derecho de familia los que dictasen sentencias en las separaciones y divorcios matrimoniales. Por otra parte, son necesarios nuevos estudios que analicen las distintas tipologías familiares, ya sean uniones entre parejas nacionales o parejas mixtas, por Comunidades Autónomas, puesto que la implantación de la custodia compartida también puede estar influenciada por estas variables (Domínguez, 2014). De acuerdo con Arce et al. (2005), una posible solución para paliar el sesgo sistemático que pueda existir en la atribución de la guarda y custodia a la madre pasa por una formación específica de los propios magistrados y de los psicólogos forenses.

En relación a la tercera hipótesis, se aprecia que los datos sugieren un incremento significativo en los razonamientos judiciales relacionados con la introducción de la Ley $25 / 2010$, al colegir la guarda y custodia compartida, al reconocimiento entre las partes en litigio y al motivar las visitas intersemanales con el progenitor no custodio. No se hallaron en el resto de razonamientos cambios significativos, lo que podría explicarse porque tales consideraciones ya se contemplaban con anterioridad a la introducción del referido texto legal. Aun tratándose de expedientes contenciosos, en los casos en que el Tribunal constató un mayor acuerdo entre las partes en relación a la coparentalidad, se atribuyó una mayor tasa de la guarda y custodia compartida. Con la necesaria reserva, cabe plantearse si la atribución de la custodia compartida pudiera ser un factor contributivo a la disminución del conflicto de la coparentalidad que redunde en el beneficio del ISM. Aunque para ello son necesarios nuevos estudios que analicen las variables con capacidad para establecer un punto de corte en relación al nivel de conflictividad asumible y dejar aquellos casos que requieran intervenciones como la coordinación de la parentalidad al ser familias que acostumbran a resolver sus conflictos mediante continuos litigios (D'Abate, 2005; Rodríguez-Domínguez y Carbonell, 2014). Lógicamente, quedan excluidas de la custodia compartida, la violencia doméstica y/o de género que la ley prohíbe expresamente (Ley 25/2010).

En relación a la cuarta hipótesis, al comparar el período 2007-2010 con el periodo 2011-2013, se observa que, pese a la ausencia de diferencias significativas, las atribuciones de la custodia compartida en expedientes contenciosos pasó del $8.3 \%$ al $17.6 \%$ lo que puede estar en consonancia con que los magistrados tienen presente la nueva legislación y el ISM aplicado a los casos concretos de las sentencias. De acuerdo con Arch y Jarne (2008), se observa que los datos apoyan la sugerencia de que el régimen de contactos preferido por los magistrados es el amplio situado en torno al $50 \%$ de los casos.

En cuanto a la quinta y sexta hipótesis los resultados ponen de manifiesto la preferencia de los informes periciales de los equipos psicosociales por la custodia exclusiva a un progenitor frente a la compartida que mostraron mayor tasa los profesionales privados, lo que abre un debate para futuros estudios que puedan profundizar en tales diferencias dada la importancia del asesoramiento especializado en la tarea auxiliar de estos profesionales a los magistrados. Respecto de la atribución en el fallo de la sentencia, las atribuciones a la madre descendieron del 75.0 del primer período hasta el 66.2 del 
período posterior, aumentando las atribuciones de la custodia compartida a más del doble (8.3 vs. 17.6), y respecto del régimen de contactos, se mantiene en torno al $50 \%$ la preferencia por un régimen amplio tal como indicaban Arch y Jarne (2008), manteniendo en estos expedientes contenciosos un régimen de contactos restringidos en una cuarta parte. Asimismo, se sugiere que parece existir una mayor confianza de los magistrados hacía los equipos psicosociales con respecto a los informes emitidos por los profesionales privados, aspecto que requiere la mayor atención para el colectivo profesional del sector privado, por cuanto es recomendable que estos profesionales sigan las recomendaciones de la 'Guía de buenas prácticas para la evaluación psicológica forense y la práctica pericial' (COPC, 2014).

En resumen, en el presente estudio los datos sugieren que los magistrados razonaron en sus sentencias los aspectos previstos por la ley, valorando la existencia de acuerdos entre las partes respecto de la coparentalidad, del régimen de contactos del menor con sus progenitores, de la pensión de alimentos, de los gastos extraordinarios para los menores, los cambios de residencia, la división de la cosa común, la atribución del mantenimiento de la vivienda para el progenitor custodio, acuerdos entre los progenitores y de éstos con los menores y las atribuciones en los fallos de las sentencias de la guarda y custodia y régimen de contactos.

Se constata que la implantación del Libro II del Código de Familia (Ley 25/2010) parece mejorar aspectos importantes en los razonamientos judiciales, destacando significativamente el triple de razonamientos en el período 2011-2013 respecto del 2007-2010 respecto de la guarda y custodia compartida, o del análisis del acuerdo entre las partes respecto de la coparentalidad en un incremento sustancial del primer al segundo período, lo cual está en consonancia con el artículo 236-17.2 de la Ley $25 / 2010$, relativo al preceptivo plan de parentalidad que han de aportar los progenitores.

En su conjunto, el análisis de las sentencias estudiadas sugiere que se han tenido en consideración: (a) las necesidades del menor en aras del ISM; (b) el análisis de la coparentalidad en referencia a las aptitudes; (c) las actitudes o carencias de los progenitores; (d) la incidencia de éstas en beneficio o detrimento del menor; (e) la valoración y funcionamiento de las necesidades del menor; y (f) el análisis de las interacciones paterno filiales, y (g) se han planteado las alternativas mejores o menos contraproducentes para el menor siempre que ha sido posible.

Aún con la salvedad de que el presente trabajo se circunscribe a siete juzgados de familia de la ciudad de Barcelona, se constata la importancia que la introduc- ción de la legislación $(25 / 2010)$ ha incrementado de forma progresiva la custodia compartida. En base a la experiencia profesional, se sugiere que los psicólogos forenses sean peritos versados en el conocimiento, no sólo psicosocial sino también jurídico, puesto que la pericia debe estar orientada a las necesidades técnicas del magistrado, de acuerdo con el art. 335 del vigente Código Civil (Ley $1 / 2000)$.

Se han de establecer las reservas y las limitaciones inherentes que no permiten la generalización de estas sentencias estudiadas al complejo de la praxis judicial. Se limitan a un momento determinado de la labor judicial en los juzgados de familia de siete juzgados de familia de la ciudad de Barcelona, no a fases consecuentes del propio proceso en otras instancias superiores, y se analizan sólo criterios estructurales de los razonamientos y las atribuciones, soslayando otros aspectos. El estudio se realizó en medio natural en el ámbito aplicado por cuanto presenta mayor validez externa y menor validez interna. Por tanto, no es posible establecer relaciones causales ni generalizar los resultados ya que es un estudio exploratorio descriptivo.

\section{Referencias}

Arce, R., Fariña, F. y Seijo, D. (2005). Razonamientos judiciales en procesos de separación. Psicothema, $17(1), 57-63$.

Arch, M. y Jarne, A. (2008). Opinión y valoración de los diferentes sistemas de guarda y custodia por psicólogos forenses y juristas españoles. Un estudio piloto. Revista de Derecho de Familia, 41, 2543.

Catalán, M. J., García, B., Alemán, C., Andreu, P., Esquiva, A., García, M. D., ... Soler, C. (2008). Custodia compartida: solicitudes de esta modalidad de custodia en procedimientos amistosos y contenciosos, desde la entrada en vigor de la nueva ley del divorcio (15/2005). En F. J. Rodríguez, C. Bringas, F. Fariña, R. Arce y A. Bernardo (Eds.), Psicología jurídica: Familia y Victimología (pp. 123-129). Oviedo, España: Servicio de Publicaciones de la Universidad de Oviedo.

Col-legi Oficial de Psicologia de Catalunya. (2014). Guía de buenas prácticas para la evaluación psicológica forense y la práctica pericial. Recuperado de http://www.copc.org/Paginas/Ficha.aspx?IdMenu= E5406E2D-6EDB-48D9-8026-30CCB62B7220 
D’Abate, D. A. (2005). Parenting Coordination : A New Service for High Conflict Divorcing Families. Intervention, 1-9.

De Torres, J. M. (2011). Custodia compartida: Una alternativa exigida por la nueva realidad social. In Dret, 4, 1-61.

Domínguez, J. A. (2014). La ruptura de matrimonios entre españoles y extranjeros con menores. Una estadística comparada. Papers, 99(2), 213234.

Instituto Nacional de Estadística. (2013). Estadistica de nulidades, separaciones y divorcios. Madrid, España: INE.

Institut de Dret Privat Europeu i Comparat. (2010). Llibre segon del Codi Civil de Catalunya. Girona, España: Universitat de Girona.

Ley 11/1981, de 13 de mayo, de modificación del Código Civil en materia de filiación, patria potestad y régimen económico del matrimonio. Boletín Oficial del Estado, A-1981-11198. Recuperado de https:/www.boe.es/boe/dias/1981/05/19/pdfs/A 10725-10735.pdf

Ley 11/1990, de 15 de octubre, sobre reforma del Código Civil en aplicación del principio de no discriminación por razón de sexo. Boletín Oficial del Estado, A-1990-25089. Recuperado de https:/www.boe.es/boe/dias/1990/10/18/pdfs/A 30527-30528.pdf

Ley $1 / 2000$, de 7 de enero de enjuiciamiento civil. Boletín Oficial del Estado, A-2000-323. Recuperado https://www.boe.es/buscar/pdf/2000/BOE-A2000-323-consolidado.pdf

Ley 15/2005, de 8 de julio, por la que se modifican el Código Civil y la Ley de Enjuiciamiento Civil en materia de separación y divorcio. Boletín Oficial del Estado, 163, 24458-24461. Recuperado de http:/www.boe.es/boe/dias/2005/07/09/pdfs/A2 4458-24461.pdf

Ley 2/2010, De 26 de mayo, de Custodia Compartida Aragonesa. Boletín Oficial del Estado, A-2010-9888. Recuperado de http://www.boe.es/boe/dias/2010/06/22/pdfs/BO E-A-2010-9888.pdf

Ley 25/2010, de 29 de julio, del libro $2^{\circ}$ del Código civil de Cataluña. Boletín Oficial del Estado, A2010-13312. Recuperado de http://www.boe.es/boe/dias/2010/08/21/pdfs/BOEA-2010-13312.pdf

Ley Foral 3/2011, de 17 de marzo, sobre custodia de los hijos en los casos de ruptura de la convivencia de los padres. Boletín Oficial del Estado, A-20116554, recuperado de https://www.boe.es/boe/dias/2011/04/12/pdfs/BOE -A-2011-6554.pdf

Ley 5/2011, de 1 de abril, de relaciones familiares de los hijos e hijas. Boletín Oficial del Estado, A2011-7329. Recuperado de http://www.boe.es/boe/dias/2011/04/25/pdfs/BOEA-2011-7329.pdf

Muñoz, A. (2011). La influencia de los sesgos cognitivos en las decisiones jurisdiccionales: El factor humano. Una aproximación. InDret, 2, 1-39.

Novo, M., Quinteiro, I. y Vázquez, M. J. (2013). ¿Cómo motivan los jueces la capacidad de los progenitores en las resoluciones judiciales? Anuario de Psicología Jurídica, 23, 47-51.

Rodríguez-Domínguez, C. y Carbonell, X. (2014). Coordinador de parentalidad: Nueva figura profesional para el psicólogo forense. Papeles del Psicólogo. 35(3), 193-200.

STS 2009/4581. (2009). Sentencia del Tribunal Supremo. Tribunal Supremo de Justicia, Sala $1^{a}$ de lo civil, Madrid.

STS 2009/7257. (2009). Sentencia del Tribunal Supremo. Tribunal Supremo de Justicia, Sala $1^{a}$ de lo civil, Madrid.

Unicef, (2013). Manual del Delegado (Mayabmun 2013) Recuperado de http://www.anahuacmayab.mx/userfiles/file/MAN UAL\%20UNICEF\%20MAYABMUN\%202013.pd $\mathrm{f}$

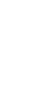

